\title{
Artificial Neural Network (ANN) of Simultaneous Heat and Mass Transfer Model during Reconstitution of Gari Granules into Thick Paste
}

\author{
S. S. Sobowale, S. O. Awonorin, T. A. Shittu, and E. S. A. Ajisegiri.
}

\begin{abstract}
Artificial neural network (ANN) based model of transient simultaneous heat and mass transfer was used for the prediction of some thermo-physical during reconstitution of gari into thick paste. Temperature changes in the paste and moisture losses were recorded over a period of two hours while the granules are being reconstituted. Data on convective heat and mass transfer coefficients were obtained during reconstitution of gari into paste. In developing the ANN model, several configurations were evaluated. The mean square error (MSE), mean absolute error (MAE) and sum square error (SSE) were used to compare the performances of the various ANN configurations. The best ANN configuration included two hidden layers, with twenty-five neurons in each hidden layer was able to produce convective heat and mass transfer coefficients values with MSE, MAE and SSE of 0.000016, 0.0029 and $0.0085 \%$, respectively, and had $R^{2}$ of 0.992 . The effectiveness of the empirical results was compared with the developed ANN model and these are valid for heat and mass transfer data obtained for the reconstitution characteristics of gari paste.
\end{abstract}

Index Terms-Artificial neural network (ANN), convective heat and mass transfer coefficient, Gari granules, modeling, reconstitution, thick paste.

\section{INTRODUCTION}

Gari is a dry granule made from roots of cassava (Manihot esculenta crantz) through a series of processing steps [1]. A versatile product, gari can be prepared in a variety of ways. It can be dispersed in cold water and consumed directly with sweeteners, groundnut and fish. The most widespread method of gari consumption is reconstituting it into a thick paste "eba" of varied consistency by pouring into a measured quantity of boiling water. The gari paste is consumed with soup or culinary dishes of various types by chewing or swallowed in morsels. It is popularly referred to as the common man's bread [2]. Observations have shown that the heat and mass transfer operations plays a prominent role during gari reconstitution processing [3], [4]. The rate of heat transfer

Manuscript received January 14, 2014; revised March 14, 2014

S. S. Sobowale is with the Department of Food Science and Technology, Moshood Abiola polytechnic, Abeokuta, Ogun State, Nigeria (e-mail: sunsam_2003@yahoo.co.uk).

S. O. Awonorin and T. A. Shittu are with the Department of Food Science and Technology, Federal University of Technology, Abeokuta, Ogun State, Nigeria.

E. S. A. Ajisegiri is with the Department of Agricultural Engineering, Federal University of Technology, Abeokuta, Ogun State, Nigeria. depends on factors such as modes of heat transfer and temperature gradient between the two bodies. The basic modes of heat transfer are conduction, convection, evaporation and radiation with radiation being the least efficient and slowest of all, since the emissivity value could only be determined at relatively high temperature (above boiling temperature of water) [5], [6]. However, the moisture transfer which is the difference in concentration of constituents throughout a solution has to be distinguished from bulk conveying by some unit operations. The application of mass transfer theory to process design and analysis of these operations is a complex engineering subject in food processing operations [7].

The reconstitution of gari into thick paste is a complicated process involving simultaneous heat and mass transfer [8]. The heat content within the vessel increases paste internal temperature and then gelatinized the granules, changing its crystalline structure into an amorphous mass. Heat and mass transfer processes are among the most important physical phenomena that occur during processing of foods. As a consequence of these processes, several important variables such as temperature and moisture concentration within the structure of food depend on time as well as on the position inside the food system. Recent study as reported by [9] on the quantitative analysis of energy transport mechanisms in steady state natural and forced convection during reconstitution of gari into thick paste showed that texture and eating quality of the thick paste are highly influenced by cassava variety, age of maturity, temperature, ratio of the quantities of water to gari sample and effectiveness in the utilization of thermal energy required by the starch to swell or form a gel. [10] explained that the knowledge of thermo-physical properties of food stuff, such as, density, specific heat, thermal conductivity, thermal and moisture diffusivity, heat and mass transfer coefficients of the material are fundamentally important in mathematical modeling, which is a based known physical principles in reducing the time and cost involved in experimentation. Mathematical modeling and computerbased numerical analyses such as, Partial Differential Equation (PDE), Response Surface Methodology (RSM) have been extensively used for the design and optimization and validation of food processing operations [10]. Though, the existing mathematical models are either too simple and hence, deviate significantly from real processes or too complex to have any practical application. It is, thus, essential to develop an artificial neural networks (ANN) model which is capable of learning from examples through iteration, incorporates large numbers of variables, and 
provides adequate and quick response to analyze the reconstitution characteristics of gari into thick paste. Such basic information is of greater value to designer of food equipment and food processors [11], [12].

The main objective of the work is to develop an Artificial neural network (ANN) based model of transient simultaneous heat and mass transfer for the prediction of convective heat and mass transfer coefficients as a function of gari reconstitution conditions (reconstitution temperatures and time, particle sizes of granule and air flow velocities). Data needed for development of the ANN model were obtained from our recent experimental work analysis of heat transfer during reconstitution of gari into paste as shown in Fig. 1.

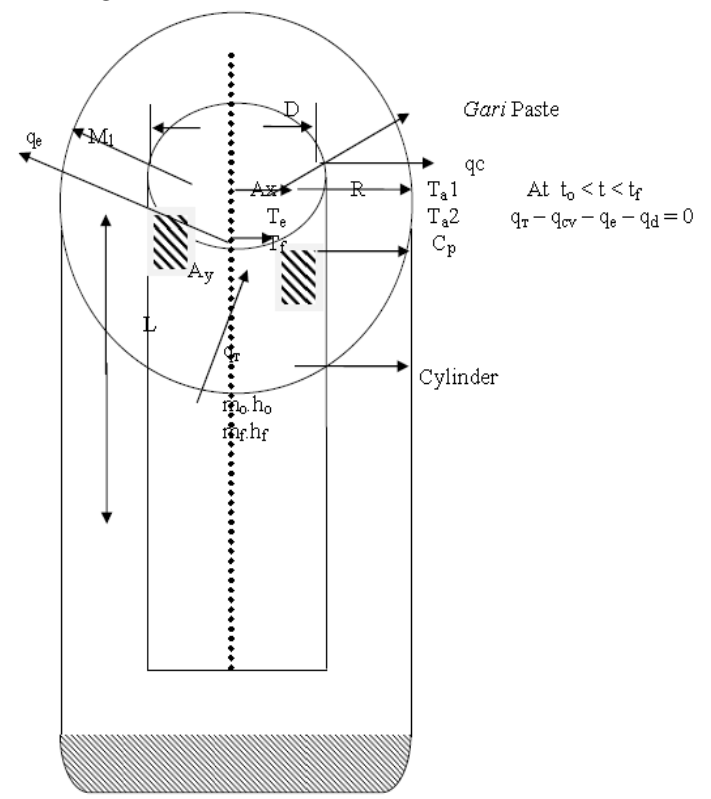

Fig. 1. A model for energy transport mechanism in a gari-water mixture during reconstitution at different temperatures [1].

\section{Methodology}

An Artificial Neural Network (ANN) based model was developed using the method described by [13], [14] for the prediction of convective heat and mass transfer coefficients during reconstitution characteristics of gari into thick paste (Fig. 2). The development of ANN model involves three basic steps: the generation of (or compilation of available) data required for training/testing, the training/testing of the ANN model, and evaluation of the ANN configuration leading to the selection of an optimal configuration, and validation of the optimal ANN model with a data set not used in training before. The procedure used for the development of our ANN model is outlined below:

\section{A. Data Generation}

Many researchers have measured thermo-physical properties of foods such as thermal diffusivity, moisture diffusivity, thermal conductivity, by various techniques. Some comprehensive reviews on the data and prediction models of thermo-physical properties have been published by [15], [16]. Convective heat and mass transfer coefficients data have been presented and modeled as a function of particle size of granules, reconstitution temperatures and time and air flow velocities during reconstitution of gari characteristics into thick paste. The convective heat and mass transfer coefficients data for the reconstitution of gari into thick paste was obtained from experimental work [17], where particle size of granules, reconstitution temperatures and time and air flow velocities information were available. The dataset was developed for training (learning) and testing of various ANN models. The dataset were organized in four columns representing particle size of granules, reconstitution temperatures and time and air flow velocities with the parameters $P, R T, R t, V$, respectively as independent (input) variables, while convective heat and mass transfer coefficients were respectively, represented by $h_{c}$ and $h_{m}$ as the dependent (output) variables. ANN models were developed and trained using these datasets. In each instance, the complete dataset was used to assess the prediction capability of a given model.

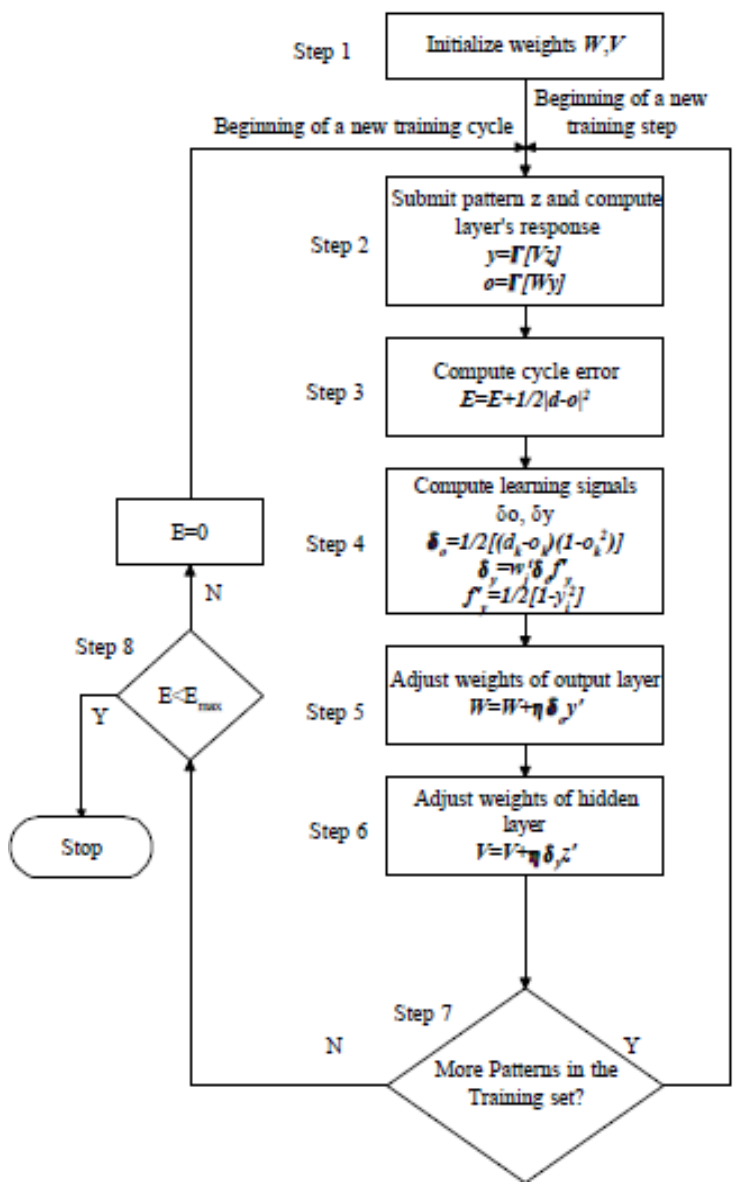

Fig. 2. A flow chart for the prediction of convective heat and mass transfer coefficients.

\section{B. Training of $A N N$}

Several ANN models were trained using the experimental data set. The feed forward network structure with input, hidden layer(s) was used in this study as shown in Fig. 3. A commercial MATLAB software package [Version 7.10.0 (R2010a) Neural Works Professional II/Plus (Neural Ware, Pittsburg, PA)] was employed. The input layer consisted of four (4) neurons which corresponded to reconstitution temperature and time, particle size and air flow velocities, while the output layers had two neurons representing the convective heat and mass transfer coefficients. The number of hidden layers and neurons within each hidden layer can be varied based on the complexity of the problem and data set. In this study, the number of hidden layers was varied 
from 1 to 2 . The neurons within each of these layers varied from 5 to 40 with increments of five. This resulted in a total of 16 networks. The optimal configuration was based upon minimizing the difference between the neural networks predicted values and the desired outputs. The data sets of 9,072 cases from the experimental method were divided in two sets. The first set consisted of 7,258 (80\%) cases for training/testing and $1,814(20 \%)$ cases for validation, chosen randomly from the set of 9,072 cases. A back propagation network algorithm was utilized in model training. A log sigmoid transfer function was used for input layers while pure-line transfer function was used for output layers. The back propagation algorithm uses the supervised training technique where the network weights $(\mathrm{Wi})$ and biases (b) are initialized randomly at the beginning of the training phases. For a given set of inputs to the network, the response to each neuron in the output layer is calculated and compared with the corresponding desired output response. The errors associated with desired output response are adjusted in the way that reduces these errors in each neuron from the output to the input layer. The error minimization process is achieved using gradient descent rule [18], [19]. To avoid the potential problem of over-training or memorization while employing feed forward algorithm, the option of saving the best configuration was selected where the network with the best result is saved during the selected long number of training cycles of 50,000 [20]-[21].

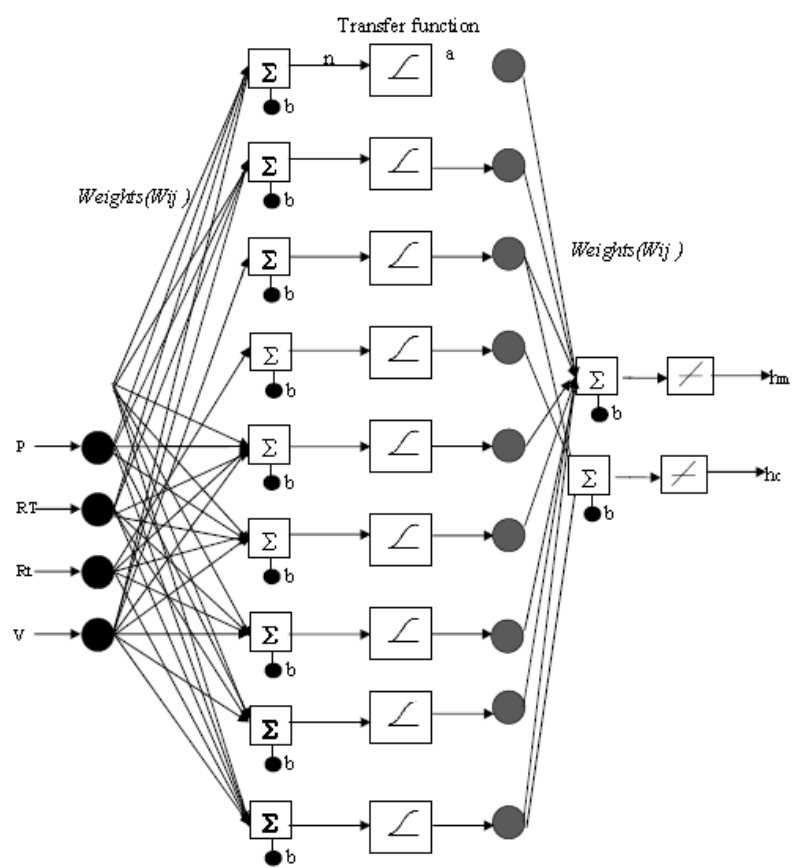

Fig. 3. Topological architectural structure of Artificial Neural Network for the prediction of convective heat and mass transfer coefficients $P=$ Particle size, $R T=$ Reconstitution temperature, $R t=$ Reconstitution time, $V=$ Air flow velocity, $h_{c}=$ Convective heat transfer coefficient, $h_{m}=$ Convective mass transfer coefficient.

\section{Selection of Optimal Configuration}

The optimal configuration was selected from 16 ANN configurations based on minimizing three error measures used to assess the predictive performance of each configuration. The performances of the various ANN configurations were compared using mean square error (MSE), mean absolute error (MAE) and sum square error (SSE). The coefficient of determination $R^{2}$, of the linear regression line between the predicted values from the neural network model and the desired output was also used as a measure of performance. The three different indicators of the model fit were defined in these equations as follows:

$$
\begin{gathered}
\mathrm{MAE}=\sum\left(M_{\mathrm{cal}}-M_{\text {pred }}\right) \\
\mathrm{MSE}=\sqrt{ } \sum\left(M_{\mathrm{cal}}-M_{\text {pred }}\right) / M_{\mathrm{cal}} \\
\mathrm{SSE}=\sqrt{ } \sum\left(M_{\mathrm{cal}}-M_{\text {pred }}\right)^{2} / N-1
\end{gathered}
$$

where,

$M_{\text {cal }}=$ Desired/calculated output by experiment

$M_{\text {pred }}=$ Predicted value by the model

$N=$ No of data points

\section{RESULTS AND DisCUSSION}

Once a given ANN configuration was trained using the input data, its performance was evaluated with the same data set. The analysis was repeated several times. The ANN configuration (out of 16) that minimized the three error measures to determine its performance, and optimized $R^{2}$, was selected as the optimum. The error measures associated with different ANN configurations for prediction of convective heat and mass transfer coefficients were presented in Table I. The best ANN configuration included two hidden layers with twenty-five neurons in each layer. The MSE, MAE and SSE for this optimal configuration with different neural networks were $0.000016,0.0029$ and $0.0085 \%$, respectively, and had $R^{2}$ of 0.992 . The simplest ANN model with one hidden layer and five neurons predicted convective heat and mass transfer coefficients with $0.00044 \%$ MSE, $0.0103 \%$ MAE and $0.22 \%$ SSE and had $\mathrm{R}^{2}$ of 0.974 , as shown in Table II. The test error which determines the amount of weight changes during series of iterations to bring the predicted value within the acceptable range of the experimental values were adjusted within the hidden layers and neurons on trial basis [22], [23]. The test error of MSE, MAE and SSE values against samples iteration number for the optimum and simplest ANN configurations were depicted in (Fig. 4 and Fig. 5). The topology which gave the minimum error in the minimum number of iterations during the training of the ANN was selected. The preliminary trial of the test error indicated that higher learning rates produced poorly developed models. These observations were similar with the published work of [24].

To reveal the credibility of prediction from the optimal ANN, correlation between the predicted versus desired values were plotted in (Fig. 6 and Fig. 7). The results demonstrated very good agreement between the predicted and desired values of convective heat transfer coefficient $\left(R^{2}=0.992\right)$ and mass transfer coefficient $\left(R^{2}=0.991\right)$. The magnitude of the errors was about the same $(\sim 10 \%)$ as the variation was significant as compare to the original experimental data. However, the prediction accuracy did not increase with increasing network parameters. The optimal network with two hidden layers and twenty-five neurons in each hidden layer had network parameters of the same order of magnitude (80\%) as the data points (126 cases). 
Considering the inherent variation in the input data set, the predicted versus desired values of the simplest ANN configuration were plotted in (Fig. 8 and Fig. 9). The simplest ANN configuration between the predicted and desired values of convective heat transfer coefficient $\left(R^{2}=\right.$ $0.975)$ and mass transfer coefficient $\left(R^{2}=0.973\right)$ were considered as a good predictor and this model is also recommended to users. The performance of the optimal neural network was validated using the remaining $20 \%$ data set $(25$ cases $)$ not previously used in the training.

However, [25]-[27] have developed ANN based model for thermal conductivity from product moisture content, particle size, temperature and bulk density for a cup cake. It had an SSE of 0.00011. The developed two equations were reported by [28]-[29], (with $R^{2}=0.98$ and 0.99 ) based on product moisture content and two different ranges of temperatures to account for a variation in thermal conductivity of flat bread. However, the ANN model developed in this present study was able to capture the variation in convective heat and mass transfer coefficients with input variables of reconstitution temperature and time, particle size and air flow velocities. In addition, the developed ANN model can be useful in the determination of heat and mass transfer rate in various types of thick paste and wide range of physical conditions.

TABLE I: NETWORK OF PARAMETERS ASSOCIATED WITH DIFFERENT ANN STRUCTURE

\begin{tabular}{|c|c|}
\hline \# Neurons in each hidden layer & \# Weight (connecting including bias) \\
\hline 5 & 11 \\
\hline 10 & 21 \\
\hline 15 & 31 \\
\hline 20 & 41 \\
\hline 25 & 51 \\
\hline 30 & 61 \\
\hline 35 & 71 \\
\hline 40 & 81 \\
\hline 5 & 17 \\
\hline 10 & 41 \\
\hline 15 & 73 \\
\hline 20 & 113 \\
\hline 25 & 161 \\
\hline 30 & 217 \\
\hline 35 & 281 \\
\hline 40 & 353 \\
\hline & \\
\hline & \\
\hline
\end{tabular}

TABLE II: ERRor PARAMETER IN THE PREDICTION OF CONVECTIVE HEAT AND MASS TRANSFER COEFFICIENTS WITH DIFFERENT NEURAL NETWORK CONFIGURATIONS

\begin{tabular}{|l|l|l|l|l|l|}
\hline Hidden layer & $\begin{array}{l}\text { Neuron layer } \\
\text { in each hidden } \\
\text { layer }\end{array}$ & MSE (\%) & MAE (\%) & SSE (\%) & $\mathbb{R}^{2}$ \\
\hline $\mathbf{1}$ & $\mathbf{5}$ & $\mathbf{0 . 0 0 0 4 4}$ & $\mathbf{0 . 0 1 0 3}$ & $\mathbf{0 . 2 2}$ & $\mathbf{0 . 9 7 4 *}$ \\
\hline 1 & 10 & 0.00170 & 0.024 & 0.91 & 0.882 \\
\hline 1 & 15 & 0.00099 & 0.0177 & 0.52 & 0.905 \\
\hline 1 & 20 & 0.00077 & 0.0140 & 0.40 & 0.899 \\
\hline 1 & 25 & 0.00068 & 0.0123 & 0.35 & 0.896 \\
\hline 1 & 30 & 0.0120 & 0.052 & $\mathbf{0 . 3 8}$ & 0.917 \\
\hline 1 & 35 & 0.00140 & 0.021 & 0.70 & 0.891 \\
\hline 1 & 40 & 0.00042 & 0.009 & 0.23 & 0.874 \\
\hline 2 & 5 & 0.00240 & 0.031 & 1.28 & 0.885 \\
\hline 2 & 10 & 0.000152 & 0.0086 & 0.08 & 0.970 \\
\hline 2 & 15 & 0.000044 & 0.0049 & 0.023 & 0.910 \\
\hline 2 & 20 & 0.000037 & 0.0043 & 0.019 & 0.897 \\
\hline $\mathbf{2}$ & $\mathbf{2 5}$ & $\mathbf{0 . 0 0 0 0 1 6}$ & $\mathbf{0 . 0 0 2 9}$ & $\mathbf{0 . 0 0 8 5}$ & $\mathbf{0 . 9 9 2}$ \\
\hline 2 & 30 & 0.000053 & 0.0036 & 0.0096 & 0.867 \\
\hline 2 & 35 & 0.00760 & 0.086 & 0.06 & 0.935 \\
\hline 2 & 40 & 0.00452 & 0.0096 & 0.047 & 0.863 \\
\hline MSE means $s q u a r e$ error; MAE means absolute & error; SSE the sum square error and $R^{2}$, the \\
\hline
\end{tabular}
MSE means square error; MAE means absolute error; SSE the sum square error and $R^{2}$, the coefficient of determination

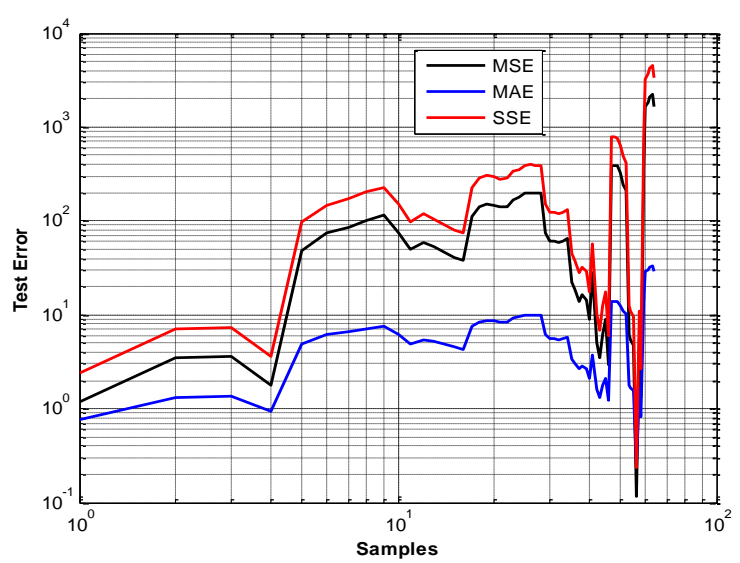

Fig. 4. Variation of MSE, MAE and SSE test error training with samples number iteration for optimum ANN configuration.

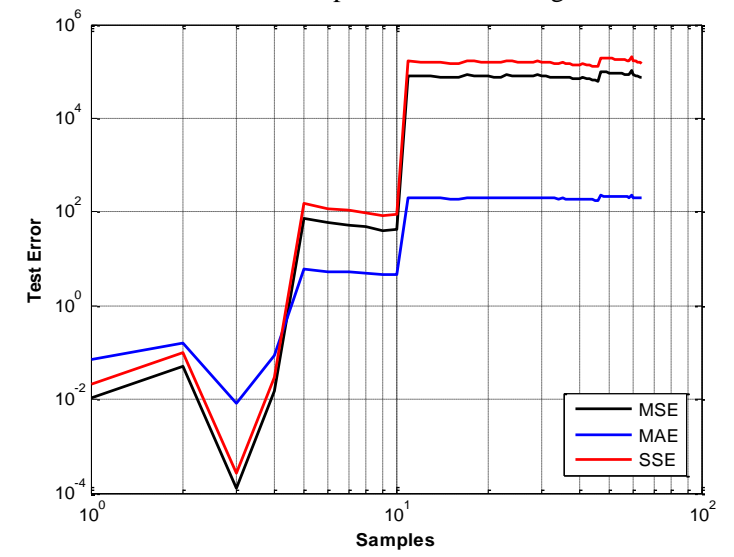

Fig. 5. Variation of MSE, MAE and SSE test error training with samples iteration number for simplest ANN configuration.

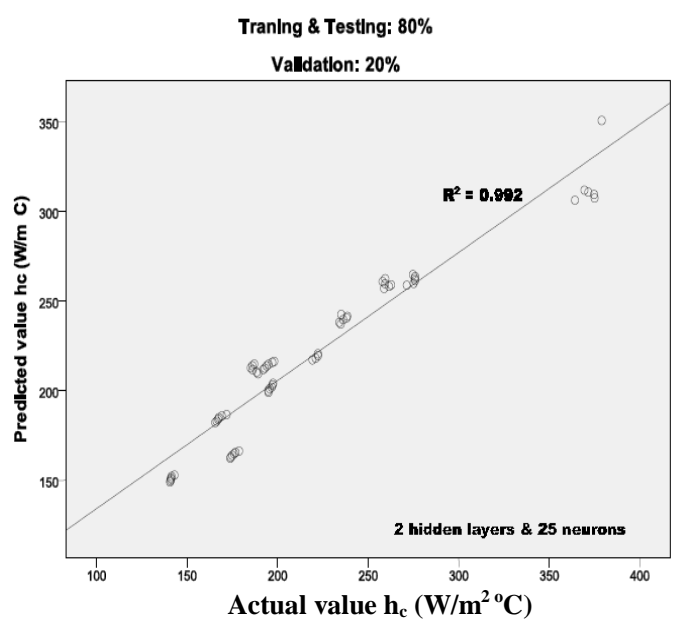

Fig. 6. Optimum ANN predicted values versus desired values of convective heat transfer coefficient with training and validation data set.

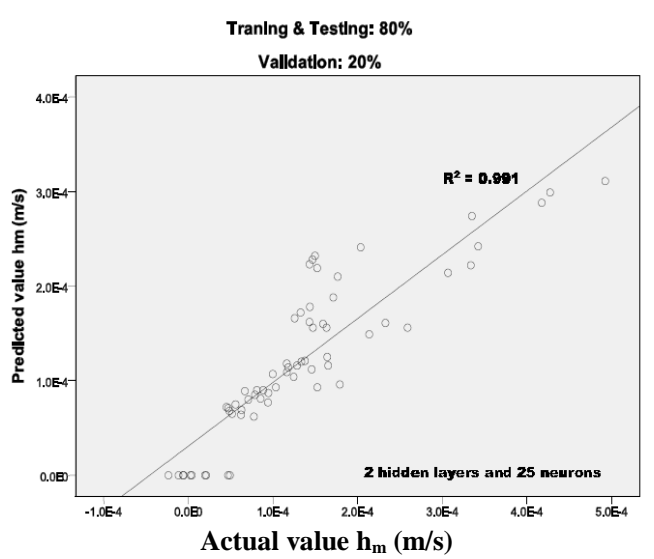

Fig. 7. Optimum ANN predicted values versus desired values of convective mass transfer coefficient with training and validation data set. 


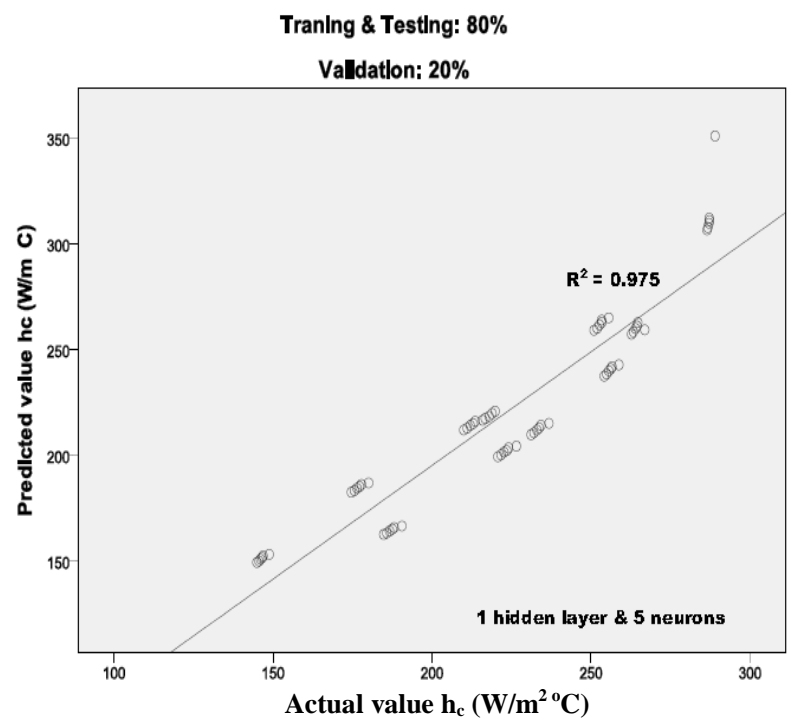

Fig. 8. Simplest ANN predicted values versus desired values of convective heat transfer coefficient with training and validation data set

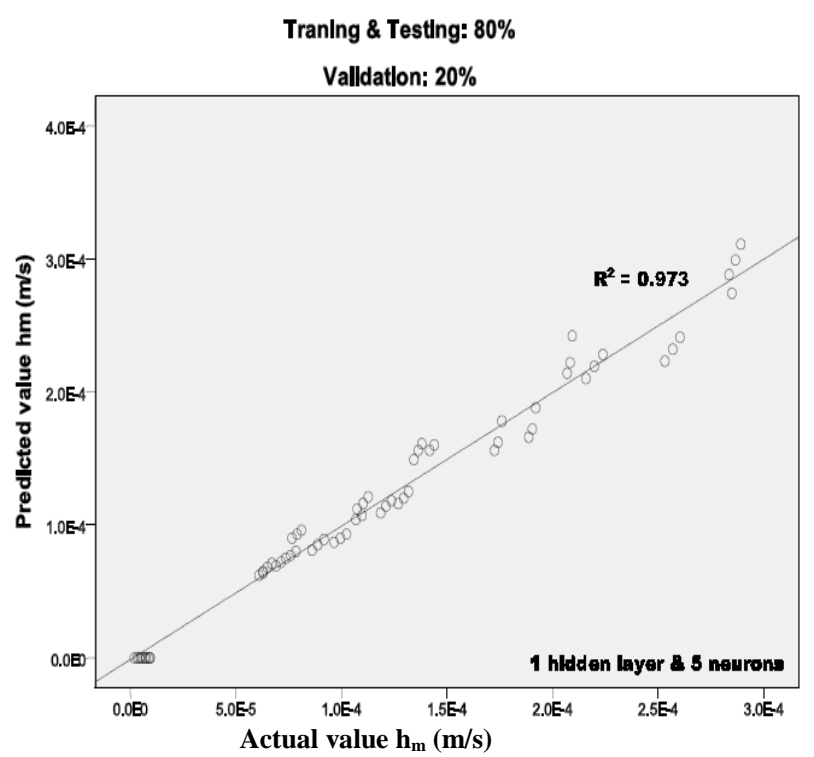

Fig. 9. Simplest ANN predicted values versus desired values of convective mass transfer coefficient with training and validation data set

\section{CONCLUSION}

An ANN model was developed for estimating convective heat and mass transfer coefficients of gari samples reconstituted at $80^{\circ} \mathrm{C}$ and $100^{\circ} \mathrm{C}$ under a wide range of reconstitution conditions. The optimum ANN model consisted of two hidden layers and twenty five neurons in each hidden layer, with mean square error (MSE), means absolute error (MAE) and sum square error (SSE) of $0.000016 \%, 0.0029 \%$ and $0.0085 \%$, respectively and had $\mathrm{R}^{2}$ of 0.992 for the reconstitution characteristics of gari into thick paste. This developed model is recommended and can be useful to estimate convective heat and mass transfer data for various types of thick paste products. These are important considerations for commercial production of gari paste and to obtain a consistent texture and eating quality of the thick paste, a desirable trend in fast food operations [30].

\section{REFERENCES}

[1] S. A. Awonorin, Food and Machinery: "From Biological systems to Physical Models in Food Preservation," 20 ${ }^{\text {th }}$ Inaugural Lecture,
Federal University of Agriculture, Abeokuta Nigeria, July, 2006, pp. 25-31.

[2] O. D. Baik, S. S. Sablani, M. Marcotte, and F. Castaign, "Modeling of thermal properties of cupcake during baking," Journal of Food Science, vol. 64, pp. 295-299, 1999.

[3] S. K. Dutta, V. K. Newa, and R. K. Bhardway, "Physical properties of Grains. Agricultural research Journal," vol. 39, pp. 128-137, 1972.

[4] M. Dornier, M. Decloux, and A. Lambert, "Interest of neural network for the optimization of the cross flow filtration process," $L W T$ - Food Science and Technology, vol. 28, issue 3, pp. 300-309, 1995.

[5] J. P. Holman, Heat Transfer, 5th ed. Mc Grawhill International Book Company London, 1997, pp. 1-48, 223-292.

[6] E. Larmond, "Laboratory methods for sensory evaluation of food, Canada," Department of Agriculture Publication, No 1637, Ottawa, 1977, pp. 54-60.

[7] P. Linko and Y. H. Zhu, "Neural network programming in bioprocess variable estimation and state prediction," Journal of Biotechnology, vol. 21, pp. 253-270, 1991.

[8] E. E. McDermott, "Non enzymatic determination of damaged starch in flour," Journal of Food Science and Agriculture, vol. 31, pp. 405413, 1980.

[9] D. G. Medcalf and K. A. Gillies, "Wheat starches 1: Comparison of physico-chemical properties," Cereal Chemistry, vol. 42, pp. 558-568, 1985 .

[10] A. M. Hussain and M. S. Rahman, "Thermal Conductivity Prediction of Fruit and Vegetables using neural networks," International Journal of Food Properties, vol. 2, issue 2, pp. 51-60, 1999.

[11] T. Hayashi, "Dynamic Response of a Cup Anemometer," Journal of Atmosphere and Oceanic Technology, vol. 4, pp. 281-287, 1986.

[12] SMS Stable Micro systems. (July 2006). [Online]. 8(2), pp. 45-56. Available: http:/www.stablemicrosystems.com.

[13] K. D. Kulkarni, D. N. Kulkarni, and U. M. Ingle, "Sorghum maltbased weaning formulations: preparation, functional properties and nultritive value," Food and Nutrition bulletin, vol. 13, pp. 322-327, 1981.

[14] J. Jaczynski and J. W. Park, "Temperature prediction during thermal processing of surimi seafood," Journal of Food Science, vol. 67, pp. 3053-3057, 2002

[15] J. N. Asegbeloyin and A. E. Onyimonyi, "The effect of fermentation time and variety on the cyanide content of cassava (Manihot esculenta Crantz)," in Proc. the 30th Annual Conference of the Nigeria Society for Animal Production, pp. 199- 200, 2005.

[16] S. S Sablani and W. H. Shayya, "Computerization of Stumbo's method of thermal process calculations suing neural networks," Journal of Food Engineering, vol. 47, pp. 233 - 240, 2001.

[17] AOAC, Association of Official Analytical Chemists, Washington DC. 15th edition, 1990, Pp. $492-498$.

[18] R. A. Anderson, "Water absorption and solubility and amylograph Characteristics of roll cooked small grain products," Cereal Chemistry, vol. 59, pp. 265-270, 1982.

[19] N. N. Moshsenin, Thermal properties of Food and Agricultural Materials, New York: Gordon and Breach Science Publisher, 1980, pp. $65-98$

[20] S. Takashi and P. A. Sieb, "Paste and gel properties of prime corn and wheat starches with and without native lipids," Cereals Chemistry, vol. 65, pp. 474-480, 1988.

[21] R. G. D. Steel and J. H. Torrie, Principle and Procedure of Statistics, $2^{\text {nd }}$ edition, New York: Mc Grawhill Book Co, 1980.

[22] N. T. Meludu, O. O. Ajani, and M. O. Akoroda, "Gari: food for the rich or poor in Nigeria," in Proc. 8th ISTRCAB Symp, Ibadan, 2001, pp. 160-169.

[23] G. Ruan, S. Almaer, and J. Zhang, "Prediction of dough Rheological properties using ANN's," Cereal Chemistry, vol. 72, pp. 308-311, 1995.

[24] L. O. Sanni and N. Olayinka, "Gari processing in Ibadan metropolis. factors controlling quality," in Proc. the International Society for Tropical Root Crops, 1994, pp. 256-261.

[25] R. S. Rapusas and R. H. Driscoll, "Thermo - physical properties of fresh and dried white onions slices," Journal of Food Engineering, vol. 24, pp. 149 - 164, 1995.

[26] R. P. Singh and D. R. Heldman, Introduction to Food Engineering, Academic Press Inc. London, 1993.

[27] S. S Sobowale, O. P. Sobukola, T. A. Shittu, S. O. Awonorin, L. O. Sanni, O. S. Awokola, and O. M. Aina, "Analysis of heat transfer during reconstitution of gari granules into a paste," Asset Journal, Series B, vol. 3, issue 2, pp. 15-26, 2006 
[28] T.-J. Lu, J.-C. Chen, C.-L. Lin, and Y.-H. Chang, "Properties of starches from cocoyam (Xanthosoma sagittifolium) tubers planted in different seasons," Food Chemistry Journal, vol. 91, pp. 69-77, 2005.

[29] C. H. Tong, S. Sheen, K. K. Shah, V. T. Huany, and D. B. Lund, "Reference material for calibrating probes used for measuring Thermal Conductivity of Frozen Foods," Journal of Food Science, vol. 58, pp. 186-192, 1993.

[30] N. P. Zogzas, Z. B. Maroulis, and D. Marinos-Kouris, "Moisture diffusivity methods of experimental determination" Drying Technology, vol. 12, pp. 483-515, 1994.

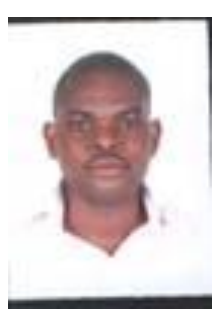

Sunday Sobowale is a lecturer at Moshood Abiola Polytechnic, Nigeria. He was born in Ibadan, Nigeria on 22 June, 1977.

He obtained master degree in food engineering in 2005, from University of Agriculture, Abeokuta, Nigeria. He has over ten (10) publications in different journals all over the globe. Currently, his $\mathrm{PhD}$ work is on "Heat and mass transfer modeling of garification" and reconstitution characteristics of gari paste.

Engr. Sobowale is a member of Nigeria Society of Nigeria (NSE) Council for the Regulation of Engineering in Nigeria (COREN) and Nigeria Institute of Food Science and Technology. 